\title{
Schedule-induced aggression against a slide-image target*
}

\author{
R.NDALL K. FLORY and BARBARA B. ELLIS \\ Hollins College. Roanoke. Ia. 24021)
}

Pigeons were trained to keypeck on a multiple schedule of reinforcement consisting of three 20-sec fixed interval components followed by one 200-sec fixed-interval component. In one phase of the study, a rear-projected slide image of a pigeon was present, while in another phase, a taxidermically prepared pigeon was present. Although more schedule-induced aggression occurred against the stuffed model than against the slide, the topography and temporal locus of attack against either target were comparable.

Several studies have shown that aggression against live or inanimate targets can be induced by the transition from frequent food reinforcement to extinction (Azrin. Hutchinson, \& Hake. 1966: Davis \& Donenfeld. 1967: Thompson \& Bloom. 1966) and by various intermittent food schedules. including fixed-ratio (Cherek \& Pickens. 1970: Cole \& Litchfeld, 1969: Cole \& Parker. 1971: Flory: 1969b: Gentry. 1968: Gentry \& Schaeffer. 1969: Hutchinson. Azrin. \& Hunt, 1968: Knutson. 1970). fixed-interval (Cherek \& Heistad. 1971: Cherek. Thompson, \& Heistad. 1973: Richards \& Rilling. 1972). variable-interval (Dove \& Rashotte. 1971). and fixed time schedules (Cherek et al. 1973: Flory. 1969a). In studies with pigeon Ss. the use of either live or stuffed targets has several disadvantages. including (1) serious injury or damage to the target. (2) uncontrolled counteraggression and/or spontaneous movement of live targets. (3) variability in the size and posture of live targets. (4) the relatively low percentage of Ss that will at tack a stuffed model. and (5) the expense of procuring live or preparing stuffed targets.

Recent demonstrations of schedule-induced aggression against a mirror (Cohen \& Looney. 1973) and against a color photograph (Looney \& Cohen. 1973) suggest that pigeons might also attack other two-dimensional objects. such as a rear-projected slide image. The slide's characteristics and availability could be easily controlled. and its use would eliminate the disadvantages of live or stuffed targets. The present study compared the amount of schedule-induced aggression exhibited against a two-dimensional slide target with that exhibited against a stuffed target.

\section{METHOD \\ Subjects}

Four experimentally naive male White Carneaux pigeons. maintained at $80 \%$ free-feeding weight. Were used. Si were approximately 5 !ears old and were housed in separate cages in a constantly illuminated room.

* This research was supported in part by National Science Foundation Endergraduate Research Participation Gran $G Y-10,000$. Requests for reprints should be sent to $R$ andall $K$. Flory. Department of Psychology. Hollins College. Roanoke. Va. 24020
One end of a pigeon chamber. similar to that described by Azrin et al (1966). con:ained a food magazine located below a standard pigeon key that could be transilluminated with red or green light. The other end of the chamber housed either of two interchangeable target objects. One target was a taxidermically prepared White Carneaux pigeon. the head and throat areas of which were covered with a white sythetic fur hood. A force of $50-55 \mathrm{~g}$ applied to the model's head closed a microswitch. The other target was a rear-projected color slide of a White Carneaux pigeon in a standing position. The head of the pigeon was rotated approximately $45 \mathrm{deg}$. thus exposing the throat and eve regions. The $35-\mathrm{mm}$ slide was projected by a Sawyer 500R projector onto a $12.1 \times 17.8 \mathrm{~cm}$ rear projection screen. A microswitch mounted on the back of the screen closed when a force of $50-55 \mathrm{~g}$ was applied to the head area of the rear-projected pigeon. For either target. only those switch closures separated by at least $0.2 \mathrm{sec}$ were recorded as discrete attacks. This contingency decreased the occurrence of switch closures due to the bounce of the stuffed target. Standard electromechanical apparatus arranged experimental events.

\section{Procedure}

To ditermine the operant level of attack prior to any schedule training. each $\mathrm{S}$ was exposed to a pretraining baseline condition. during which the slide target was initially available and during which the response key was inoperative and dark. When attack rate stabilized over five 1.5 -h sessions with little or no systematic variability. the slide target was removed and the stuffed model introduced. Following stability of attack rate against the stuffed target. the slide target was reintroduced to determine whether prior exposure to the ituffed model would facilitate attack against the slide target. A second presentation of the stuffed model constituted the last phase of the pretraining baseline condition.

With neither target present in the chamber. Ss were magazine trained and then trained to kerpeck on a multiple schedule. consisting of three 20-sec fixed-interval (FI) schedule components correlated with a red key. followed by one 200-sec FI schedule component correlated with a blue ker. Exposure to the multiple schedule continued until the rate and index of curvature (Fry. Kelleher. \& Cook. 1960) of keypecking each showed stability over five sessions. The slide target was then presented until rate of attack against it was stable. In the last condition of the study. the stuffed target was available during the ongoing multiple FI 20-sec FI 200-sec schedule. Each session consisted of 45 1 $120-\mathrm{sec}$ components and 15 FI 200-sec components. for a total of 60 reinforcements.

\section{RESULTS}

Figure 1 shows session attack rates of Pigeons AC8 and AC9. Figure 1 shows session attack rates of Pigeons $\mathrm{AC} 8$ and $\mathrm{AC}$. The data from the other two Ss are not presented because these Ss never attacked either target throughout the entire study. As Fig. 1 shows. Ss AC8 and AC9 exhibited relatively little operant-level attack against either target. The initial high attack rates of Bird AC8 against the stuffed target during the second and fourth phases of the baseline condition dropped to zero over sessions. On the first session of exposure to the multiple FI 20-sec FI 200-sec schedule. Pigeons AC8 and AC9 emitted 7 and $H$ attacks. respectively. against the slide target. For both Ss. all attacks occurred during the 


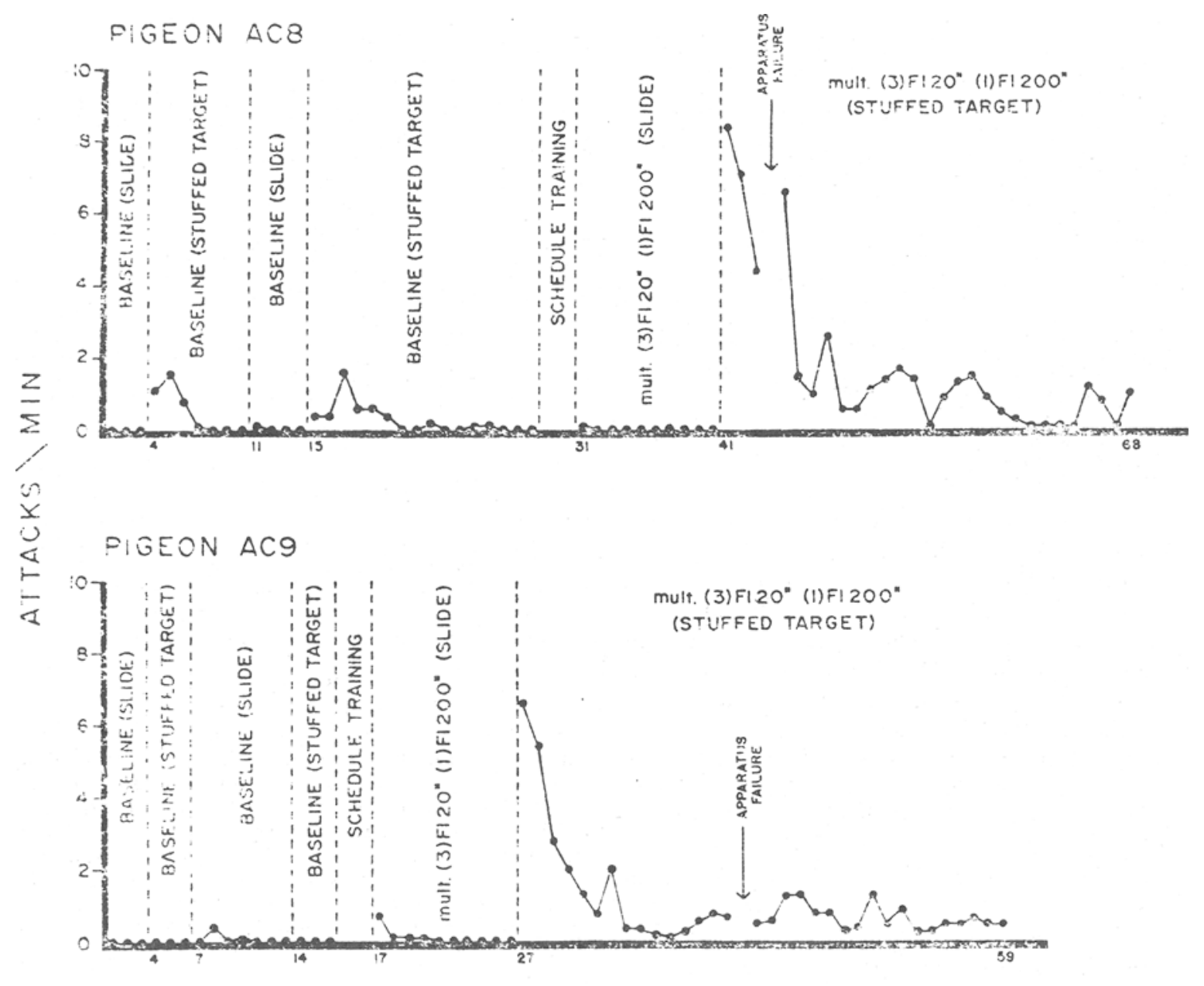

SESSIONS

Fig. 1. Overall rate of attack (total attacks/session duration) for Pigeons AC8 and AC9.

blue-key stimulus condition correlated with the FI 200-sec schedule component. With continued exposure to this condition, attack against the slide image dropped to zero or near zero levels for both Ss. When the stuffed target was then introduced, the attack behavior of each $\mathrm{S}$ initially showed a substantial increase. With further exposure, however, attack decreased to low levels for both birds.

Figure 2 shows sample cumulative records of Pigeon AC9. Similar records were obtained from Pigeon AC8. The upper channel of each record shows keypecking and attack behavior. Each keypeck steps the recorder pen cumulatively in an upward direction, and each reinforcement resets the pen. Attacks are indicated by brief downward deflections of the response pen. In the lower channel of each record, the event pen is down during the FI 20-sec component and up during the FI 200-sec component of the multiple schedule. As Fig. 2 indicates, attacks against either target predominantly occurred shortly after the onset of the
FI 200-sec schedule. Attacks by either pigeon seldom occurred during FI 20-sec-schedule components. During the 10 sessions of exposure to the multiple-schedule/slide-target condition, the per cent of FI 200-sec components in which attack occurred was 3 . for Bird AC8, and 12, for Bird AC9. Neither S attacked the slide target in any of the FI 20-sec schedule components. During the multiple-schedule/stuffed-target condition, the percent of FI 200 -sec components that included at least one attack was 41 for each S. Ss attacked the stuffed model in less than $1 \%$ of the FI 20-sec components occurring in this last experimental condition, and showed a general tendency to attack in the former rather than in the latter portions of daily sessions.

Visual observation during sessions revealed that at tacks were primarily directed against the head region of either target. Similar findings have been reported for live targets (Azrin et al, 1966: Cherek et al, 1973; Gentry, 1968), stuffed models (Dove \& Rashotte. 1971: 


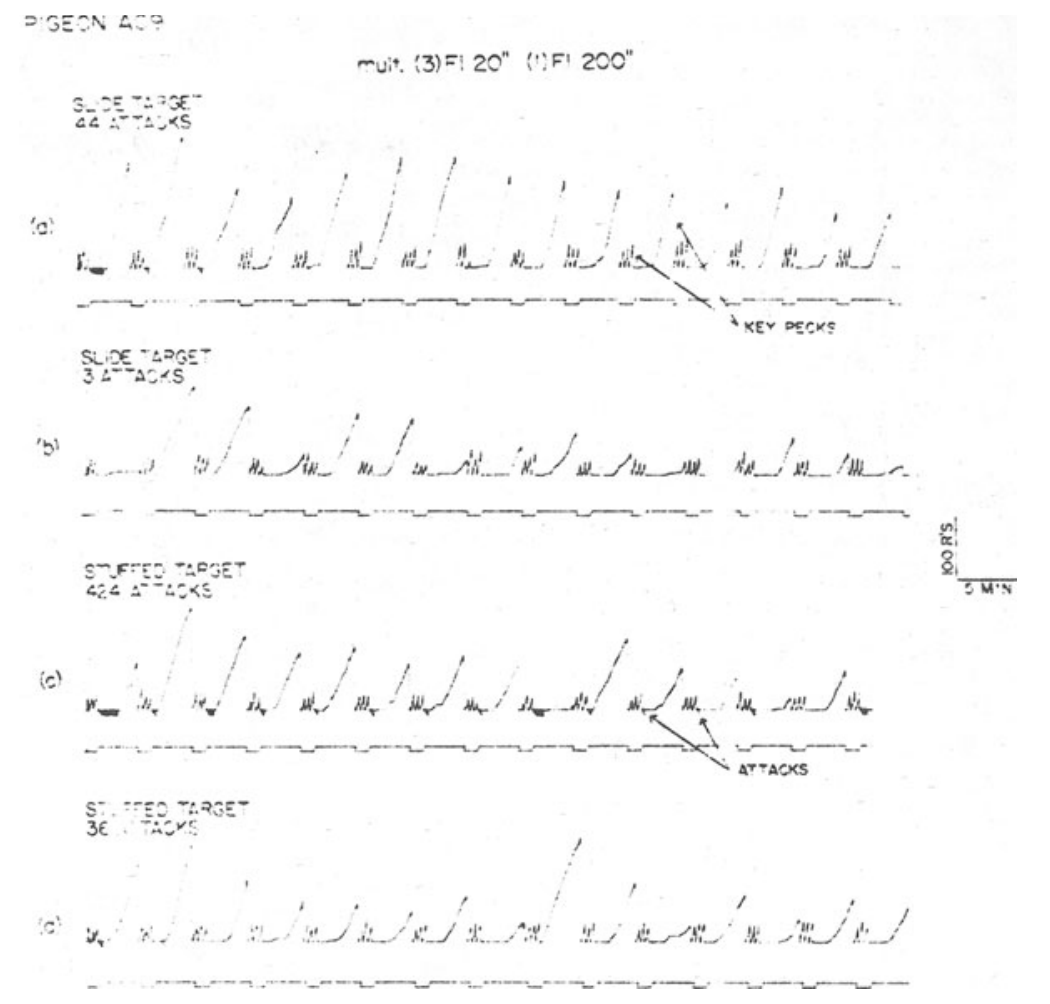

Fig. 2. Sample cumulative records of Pigeon AC9. Records (a) and (b) show, respectively, the first and last session of the multiple-schedule/slide-target condition, whereas Records (c) and (d) show, respectively, the first and last sessions of the multiple-schedule/stuffed-target condition.
Flory, 1969a,b), mirror-image targets (Cohen \& Looney, 1973), and pictorial targets (Looney \& Cohen, 1973).

\section{DISCUSSION}

The results of the present study tentatively suggest that a rear-projected image of a conspecific is a relatively ineffective target for the study of schedule-induced aggression in pigeons. The two Ss that did attack either target showed a considerably lower rate of responding against the slide image than against the stuffed model. In a preliminary study similar to the present one. Rashotte, Katz. \& Griffin (1973) reported that only two of their eight pigeons exhibited substantial extinction- or schedule-induced aggression against a rear-projected image of a pigeon. Although these two Ss had a previous history of pecking a key and a stuffed pigeon to obtain food. their screen contacts showed the same topography and postreinforcement occurrence as the attack behavior of Pigeons AC8 and AC9 in the present study. In general. both studies indicate that pigeons show little or no schedule-induced aggression against a two-dimensional slide-image target.

The observations of schedule-induced attack against a mirror (Cohen \& Looney, 1973) and against a color photograph (Looney \& Cohen. 1973) suggest that neither the hard surface nor the two-dimensionality of the slide target was responsible for the low levels of attack on it. It is possible that less attack occurred against the slide target than against the stuffed pigeon. because the feedback movement or bounce following blows on the stuffed model was absent following contacts on the glass screen. The observation (Looney \& Cohen. 1973) that pigeons will attack a stationar! color photograph of a conspecific suggests. however. that feedback movement of the target is not necessary for schedule-induced aggression to occur against it. It is also possible that the size of the projected image target may be a critical determinant of the amount of schedule-induced attack against it. That is, a projected image may not be perceived as lifelike unless its size on the contact screen is essentially equal to that of a live or stuffed target pigeon. Other factors, such as the orientation, brightness, and color of the projected image. may also be critical to its being an effective target of schedule-induced aggression.

Upon initial exposure to either target object. the rates of attack for Pigeons AC8 and AC9 were maximal. Over sessions. however, target contacts progressively decreased to low or zero levels for both Ss. Using pigeon $S$ s and fixed-ratio (FR) food schedules, Cherek \& Pickens (1970) reported a similar gradual decrease in attack against a live target following each increase of the FR response requirement. The results of these two studies suggest that schedule-induced aggression against live or inanimate targets may be a relatively unstable behavior which varies inversely with amount of exposure to experimental conditions.

In summary, the present study was conducted to investigate whether a rear-projected slide image would serve as an adequate target of schedule-induced attack. Although the results indicate that a slide target was not as effective as a stuffed model. further research with additional food schedules is necessary before definite conclusions can be reached.

\section{REFERENCES}

Azrin. N. H., Hutchinson, R. R.. \& Hake. D. F Extinction-induced aggression. Journal of the Experimental Analysis of Behavior, $1966,9,191-204$

Cherek, D. R., \& Heistad, G. T. Fixed-interval-induced aggression. Psychonomic Science. 1971. 25, 7-8.

Cherek, D. R. \& Pickens, R. Schedule-induced aggression as a function of fixed-ratio value. Journal of the Experimental Analysis of Behavior, 1970, 14, 309-311.

Cherek, D. R., Thompson. T., \& Heistad. G. T. Responding maintained by the opportunity to attack during an interial food reinforcement schedule. Journal of the Experimental Analysis of Behavior, 1973, 19.113-123.

Cole. J. M.. \& Litchfield, P. M. Stimulus control of schedule-induced aggression in the pigeon. Psychonomic Science. 1969, 17, 152-153

Cole. J. M.. \& Parker. B. K. Schedule-induced aggression: Access to an attackable target bird as a positive reinforcer. 
Psychonomic Science, 1971.22. 33-35

Cohen. P. S.. \& Looner. T. A Schedule-induced mirror responding in the pigeon. Journal of the Experimental Analysis of Behavior. 1973, 19, 395-408

Davis. H.. \& Donenfeld. I. Extinction induced social interaction in rats. Psychonomic Science. $1967.7 .85-86$.

Dove. L. D.. \& Rashotte. II. E. Attack in pigeons during variable-interval food reinforcement schedules. Paper presented at the annual meeting of the Eastern Psychological Association. New York City. April 1971

Flory, R. K. Attack as a function of minimum inter-food interial. Journal of the Experimental Analysis of Behavior. 1969a. 12.825-828

Flory. R. K. Attack behavior in a multiple fixed-ratio schedule of reinforcement. Psvchonomic Science, 1969b, 16, 156-157.

Fry. W.. Kelleher. R. T.. \& Cook. L. A mathematical index of performance on fixed-interial schedules of reinforcement. Journal of the Experimental Analysis of Behavior. 1960. 3. 193-199.

Gentry. W. D. Fixed-ratio schedule-induced aggression. Journal of the Experimental Analysis of Behavior 1968, 11.813-817.

Gentry. W. D.. \& Schaeffer. R. W. The effect of $F R$ response requirement on aggressive behavior in rats. Psychonomic Science. $1969.14 .236 \& 238$

Hutchinson. R. R. Azrin, N. H. \& Hunt. G. M. Attack produced by intermittent reinforcement of a concurrent operant response. Journal of the Experimental Analysis of Behatior. 1968. 11. $489-495$

Knutson. J. F. Aggression during the fixed-ratio and extinction components of a multiple schedule of reinforcement. Journal of the Experimental Analysis of Behatior. 1970.13,221-231.

Looney. T. A.. \& Cohen. P. S. Maintenance of schedule-induced attack on pictorial targets by pigeons. Paper presented at the annual meeting of the Eastern Psychological Association. Washington. D.C... May 1973

Rashotte. M. E.. Katz. H. N.. \& Griffin. R. W. A preliminary report on the effect of some target variables on schedule-induced attack. Paper presented at the annual meeting of the Southeastern Psychological Association. New Orleans. April 1973

Richards. R. W.. \& Rilling. M. Aversive aspects of a fixed-interval schedule of food reinforcement. Journal of the Experimental Analysis of Behavior. 1972.17.405-411

Thompson. T. \& Bloom. W. Aggressive behavior and extinction-induced response-rate increase. Psvchonomic Science. $1966,5,335-336$.

(Received for publication July 20. 1973.) 